Trinity University

Digital Commons@ Trinity

Chemistry Faculty Research

Chemistry Department

$11-7-2003$

\title{
Dendrimer-Encapsulated Nanoparticle Precursors to Supported Platinum Catalysts
}

Huifang Lang

Trinity University

R Alan May

Trinity University

Brianna L. Iversen

Trinity University

Bert D. Chandler

TrinityUniversity, bchandle@trinity.edu

Follow this and additional works at: https://digitalcommons.trinity.edu/chem_faculty

Part of the Chemistry Commons

\section{Repository Citation}

Lang, H., May, R. A., Iversen, B. L., \& Chandler, B. D. (2003). Dendrimer-encapsulated nanoparticle precursors to supported platinum catalysts. Journal of the American Chemical Society, 125(48), 14832-14836

This Article is brought to you for free and open access by the Chemistry Department at Digital Commons @ Trinity. It has been accepted for inclusion in Chemistry Faculty Research by an authorized administrator of Digital Commons @ Trinity. For more information, please contact jcostanz@trinity.edu. 


\title{
Dendrimer-Encapsulated Nanoparticle Precursors to Supported Platinum Catalysts
}

\author{
Huifang Lang, R. Alan May, Brianna L. Iversen, and Bert D. Chandler* \\ Contribution from the Department of Chemistry, Trinity University, One Trinity Place, \\ San Antonio, Texas 78212-7200
}

Received May 29, 2003; E-mail: bert.chandler@trinity.edu

\begin{abstract}
In this contribution, we report the successful preparation of supported metal catalysts using dendrimer-encapsulated Pt nanoparticles as metal precursors. Polyamidoamine (PAMAM) dendrimers were first used to template and stabilize Pt nanoparticles prepared in solution. These dendrimer-encapsulated nanoparticles were then deposited onto a commercial high surface area silica support and thermally activated to remove the organic dendrimer. The resulting materials are active oxidation and hydrogenation catalysts. The effects of catalyst preparation and activation on activity for toluene hydrogenation and $\mathrm{CO}$ oxidation catalysis are discussed.
\end{abstract}

\section{Introduction}

Polyamidoamine (PAMAM) dendrimers have drawn considerable interest in recent years due to their potential applications in medicine, nanotechnology, and catalysis. ${ }^{1-5}$ These macromolecules can also be functionalized to incorporate transition metal complexes into the dendrimer backbone; such functionalized dendrimers have shown a variety of novel properties when employed as homogeneous catalysts. ${ }^{4,5}$ Functionalized or modified PAMAM dendrimers can also be immobilized on solid supports and employed as "heterogenized" homogeneous catalysts. ${ }^{6-8}$

The ability to control dendrimer interior/exterior functionalities and the macromolecular architecture of PAMAM dendrimers (open spaces within the interior) also create an ideal environment for trapping guest species. ${ }^{9,10}$ Specifically, PAMAM dendrimers can bind a defined number of transition metal cations and thus template and stabilize metal oxide or metal nanoparticles. ${ }^{3,11,12}$ Templated $\mathrm{Pt}, \mathrm{Pd}$, and $\mathrm{Pt}-\mathrm{Pd}$ nanoparticles have been employed as homogeneous catalysts, ${ }^{13-17}$ and tem-

(1) Zeng, F.; Zimmerman, S. C. Chem. Rev. 1997, 97, 1681

(2) Bosman, A. W.; Janssen, H. M.; Meijer, E. W. Chem. Rev. 1999, 99, 1665.

(3) Crooks, R. M.; Lemon, B. I.; Sun, L.; Yeung, L. K.; Zhao, M. Top. Curr. Chem 2001, 212, 82-135.

(4) Twyman, L. J.; King, A. S. H.; Martin, I. K. Chem. Soc. Rev. 2002, 31, 69-82.

(5) Kreiter, R.; Kleij, A. W.; Gebbink, R. J. M.; van Koten, G. Top. Curr. Chem 2001, 217, 163-199.

(6) Chung, Y.-M.; Rhee, H.-K. Chem. Commun. 2002, 238-239.

(7) Antebi, S.; Arya, P.; Manzer, L. E.; Alper, H. J. Org. Chem. 2002, 67, 6623-6631.

(8) Alper, H.; Arya, P.; Borque, S. C.; Jefferson, G. R.; Manzer, L. E. Can. J. Chem. 2000, 78, 920-924.

(9) Fisher, M.; Vogtle, F. Angew. Chem., Int. Ed. Engl. 1999, 38, 884

(10) Cooper, A. I.; Londono, J. D.; Wignall, G.; McClain, J. B.; Samulski, E. T.; Lin, J. S.; Dobrynin, A.; Rubinstein, M.; Burke, A. L. C.; Frechet, J. M. J.; DeSimone, J. M. Nature 1997, 389, 368-371.

(11) Crooks, R. M.; Zhao, M.; Sun, L.; Chechik, V.; Yeung, L. K. Acc. Chem. Res. 2001, 34, 181-190.

(12) Ottaviani, M. F.; Montalti, F.; Turro, N. J.; Tomalia, D. A. J. Phys. Chem. $B$ 1997, 101, 158-166.

(13) Yeung, L. K.; Lee, C. T.; Johnston, K. P.; Crooks, R. M. Chem. Commun. 2001, 21, 2290-2291.

(14) Rahim, E. H.; Kamounah, F. S.; Frederiksen, J.; Christensen, J. B. Nano Lett. 2001, 1, 499-501. plated iron oxide nanoparticles have been used as precursors for the synthesis of carbon nanotubes. ${ }^{18}$ In this manuscript, we report a new application of dendrimer-encapsulated nanoparticles: as precursors to supported metal particle catalysts (Scheme 1).

Finely dispersed metal nanoparticles supported on inorganic oxide carriers are a mainstay of commercial heterogeneous catalysts. ${ }^{19}$ These supported-metal catalysts are generally prepared via impregnation of metal salts onto an oxide support, followed by high-temperature oxidation and/or reduction. ${ }^{19}$ Because such methods are relatively inexpensive, they are widely applied with numerous metals and supports; however, they provide limited control over particle size and distribution in the ultimate catalyst. This is a considerable drawback to studying and understanding the catalytic mechanisms at work on these catalysts.

Dendrimer-encapsulated metal nanoparticles (DENs), on the other hand, can be prepared in solution with reproducible and variable synthetic schemes. Utilizing DENs as catalyst precursors offers the opportunity to exert a degree of control over metal particle size and composition, while varying the carrier or substrate (see Scheme 1). The potential to ultimately control nanoparticle size and composition ${ }^{11,17,20}$ makes DENs extremely attractive as potential precursors for studying supported-metal catalysts. Because the particles are prepared ex situ and can be deposited onto a substrate or support, DENs offer the opportunity to bridge the gap between surface science studies of model systems and real world catalysts on high surface area

(15) Ooe, M.; Murata, M.; Mizugaki, T.; Ebitani, K.; Kaneda, K. Nano Lett. 2002, 2, 999-1002.

(16) Niu, Y. H.; Yeung, L. K.; Crooks, R. M. J. Am. Chem. Soc 2001, 123 6840-6846.

(17) Chung, Y.-M.; Rhee, H.-K. Catal. Lett. 2003, 85, 159-164.

(18) Choi, H. C.; Kim, W.; Wang, D.; Dai, H. J. Phys. Chem. B 2002, 106 12361-12365.

(19) Ponec, V.; Bond, G. C. Catalysis by Metals and Alloys; Elsevier: Amsterdam, 1995; Vol. 95.

(20) Scott, R. W. J.; Datye, A. K.; Crooks, R. M. J. Am. Chem. Soc. 2003, 123, 3708-3709.

10.1021/ja0364120 CCC: $\$ 25.00$ @ 2003 American Chemical Society

14832 - J. AM. CHEM. SOC. 2003, 125, 14832-14836 
Scheme 1. Schematic Route to Dendrimer-Derived Supported Nanoparticle Catalysts

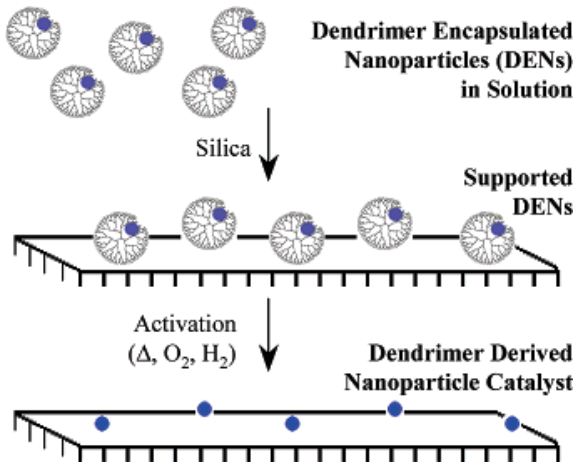

supports. The possibility of varying particle size and composition through nanoparticle preparation schemes makes DENs uniquely suited to exploring and understanding the relative importance of these effects on catalytic reactions using materials comparable to those employed as industrial catalysts. In this manuscript, we report the initial proof of this concept using dendrimerencapsulated Pt nanoparticles.

\section{Results}

Generation 5 PAMAM dendrimers $(\mathrm{G} 5-\mathrm{OH})$ were used to prepare dendrimer-encapsulated Pt nanoparticles (DENs) via literature procedures. ${ }^{11}$ Two samples were prepared in aqueous solution using Pt:dendrimer ratios of 100:1 $\left(\mathrm{Pt}_{100}\right)$ and 50:1 $\left(\mathrm{Pt}_{50}\right)$. After purification by dialysis, the Pt content of the DEN solutions was determined via AA spectroscopy. DENs were then deposited onto DAVICAT SI- 1403 silica via wetness impregnation to make $0.3 \mathrm{wt} \% \mathrm{Pt}$ materials. Because the DEN preparation procedures utilized very dilute $\mathrm{G} 5-\mathrm{OH}$ solutions, impregnation of DEN solutions onto the silica required condensing the solutions prior to deposition. For comparison purposes, a standard supported $\mathrm{Pt}$ catalyst was prepared via insipient wetness impregnation of $\mathrm{H}_{2} \mathrm{PtCl}_{6}$ onto the same silica support.

The supported, intact DENs do not bind $\mathrm{CO}$ and are not active catalysts. Presumably, in the absence of solvent, the dendrimer collapses onto the nanoparticle, preventing even small substrates from accessing the metal surface. ${ }^{21}$ Activation conditions for the supported DENs were chosen on the basis of thermal decomposition experiments in a controlled atmosphere transmission IR cell. Destruction of the dendrimer amide linkages was followed while heating under flowing $\mathrm{O}_{2} / \mathrm{He}$ by monitoring spectral changes in the $1750-1500 \mathrm{~cm}^{-1}$ region. Figure 1 shows the onset of dendrimer decomposition began near $75{ }^{\circ} \mathrm{C}$; however, the spectrum continued to change until the sample had been treated at $300{ }^{\circ} \mathrm{C}$ for several hours.

On the basis of these results, samples were oxidized with flowing $\mathrm{O}_{2} / \mathrm{He}$ at $300{ }^{\circ} \mathrm{C}$ for $4 \mathrm{~h}$. As shown in Figure 2, $\mathrm{Pt}_{50} /$ $\mathrm{SiO}_{2}$ and $\mathrm{Pt}_{100} / \mathrm{SiO}_{2}$ subjected to this oxidation treatment showed very similar activity for $\mathrm{CO}$ oxidation catalysis but were less active than the traditionally prepared catalyst. Further treatment with flowing $\mathrm{H}_{2}$ yielded materials that bind $\mathrm{CO}$ and are much more active catalysts (vida infra). On the basis of these results, we used an activation protocol involving an oxidation step $\left(\mathrm{O}_{2}\right.$, $\left.300{ }^{\circ} \mathrm{C}, 4 \mathrm{~h}\right)$ and a reduction step $\left(\mathrm{H}_{2}, 300{ }^{\circ} \mathrm{C}, 2 \mathrm{~h}\right)$ to yield the dendrimer-derived nanoparticle catalysts (DDNCs) $\mathrm{Pt}_{50} / \mathrm{SiO}_{2}$ and

(21) Deutsch, S. D.; Lafaye, G.; Lang, H.; Chandler, B. D.; Liu, D.; Williams, C. T.; Gao, J.; Murphy, C. J.; Amiridis, M. D. Langmuir 2003, submitted.

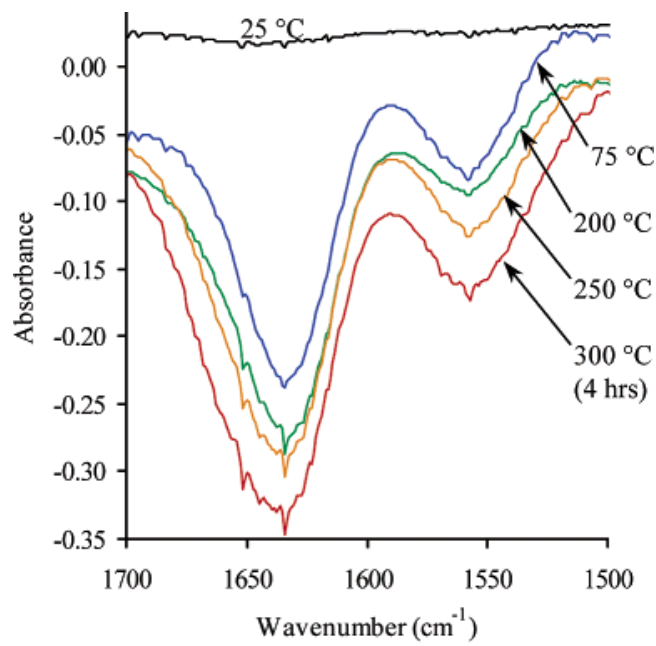

Figure 1. Infrared spectra showing dendrimer decomposition under flowing $\mathrm{O}_{2} / \mathrm{He}$.

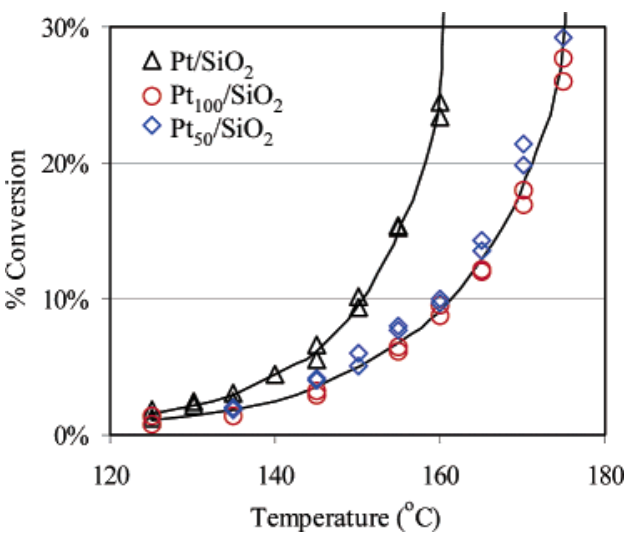

Figure 2. $\mathrm{CO}$ oxidation catalysis after oxidation at $300{ }^{\circ} \mathrm{C}$ for $4 \mathrm{~h}$.

Table 1. Characterization Data

\begin{tabular}{|c|c|c|c|}
\hline & $\mathrm{Pt} / \mathrm{SiO}_{2}$ & $\mathrm{Pt}_{100} / \mathrm{SiO}_{2}$ & $\mathrm{Pt}_{50} / \mathrm{SiO}_{2}$ \\
\hline \multicolumn{4}{|c|}{ Elemental Analysis } \\
\hline$\% \mathrm{Pt}$ & 0.25 & 0.30 & 0.32 \\
\hline$\% \mathrm{C}$ & 0 & $<0.5$ & $<0.5$ \\
\hline$\% \mathrm{~N}$ & & $<0.2$ & $<0.2$ \\
\hline \multicolumn{4}{|c|}{ CO Adsorption Data } \\
\hline$v_{\mathrm{CO}}\left(\mathrm{cm}^{-1}\right)$ & 2074 & 2082 & 2078 \\
\hline $\begin{array}{l}\text { peak width at } \\
\text { half-height }\left(\mathrm{cm}^{-1}\right)\end{array}$ & 57 & 23 & 30 \\
\hline dispersion $(\%)$ & 43 & 66 & 49 \\
\hline$d_{\text {calc }}(\mathrm{nm})$ & 2.5 & 1.7 & 2.3 \\
\hline \multicolumn{4}{|c|}{ TEM } \\
\hline supported DENs $^{a}$ & & $1.9 \pm 0.3$ & $2.1 \pm 0.6$ \\
\hline activated catals & $2.9 \pm 1.5$ & $2.2 \pm 0.5$ & $2.2 \pm 0.5$ \\
\hline
\end{tabular}

${ }^{a}$ Average diameter with standard deviation.

$\mathrm{Pt}_{100} / \mathrm{SiO}_{2}$. Elemental analysis of these catalysts (Table 1) shows the $\mathrm{C}$ and $\mathrm{N}$ content to be below the detection limits. The traditionally prepared $\mathrm{Pt} / \mathrm{SiO}_{2}$ catalyst was also activated under these conditions and contained less than $500 \mathrm{ppm}$ of $\mathrm{Cl}$ after activation.

Infrared spectra of $\mathrm{CO}$ adsorbed to the activated catalysts are presented in Figure 3; the peak shapes are evaluated by the peak widths at half-height in Table 1. Particle size distribution histograms from TEM data on supported DENs and activated DDNCs are compared with the traditionally prepared catalyst in Figure 4. Further characterization data, including elemental 

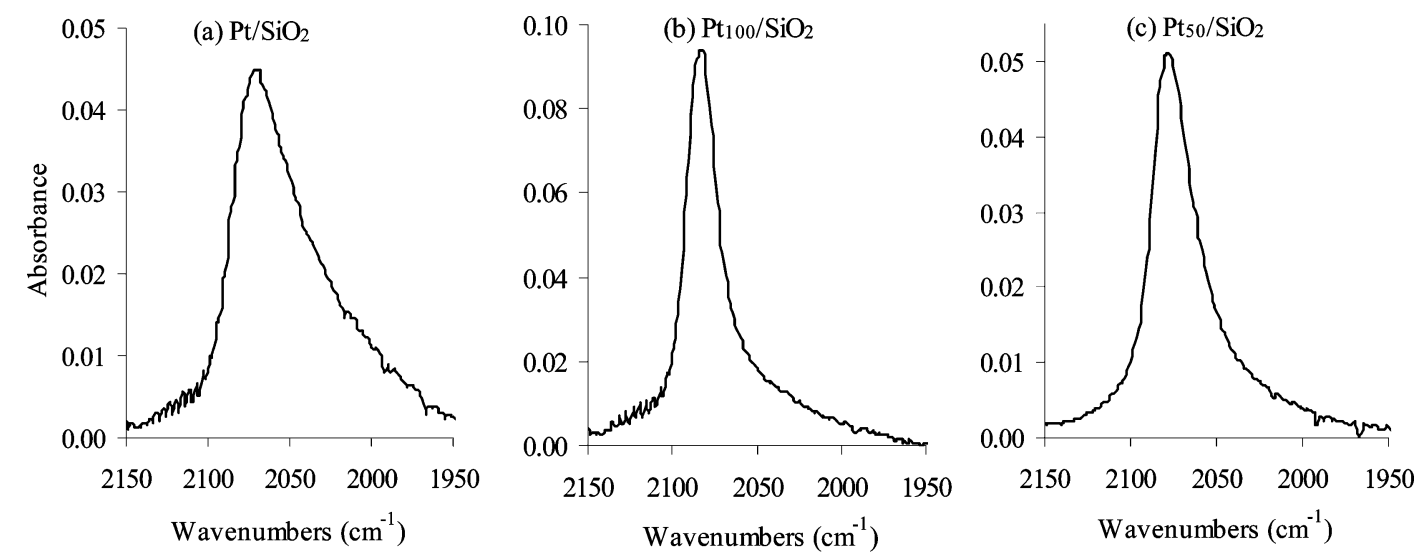

Figure 3. Infrared spectra of $\mathrm{CO}$ adsorbed on (a) $\mathrm{Pt} / \mathrm{SiO}_{2}$, (b) $\mathrm{Pt}_{100} / \mathrm{SiO}_{2}$, and (c) $\mathrm{Pt}_{50} / \mathrm{SiO}_{2}$.
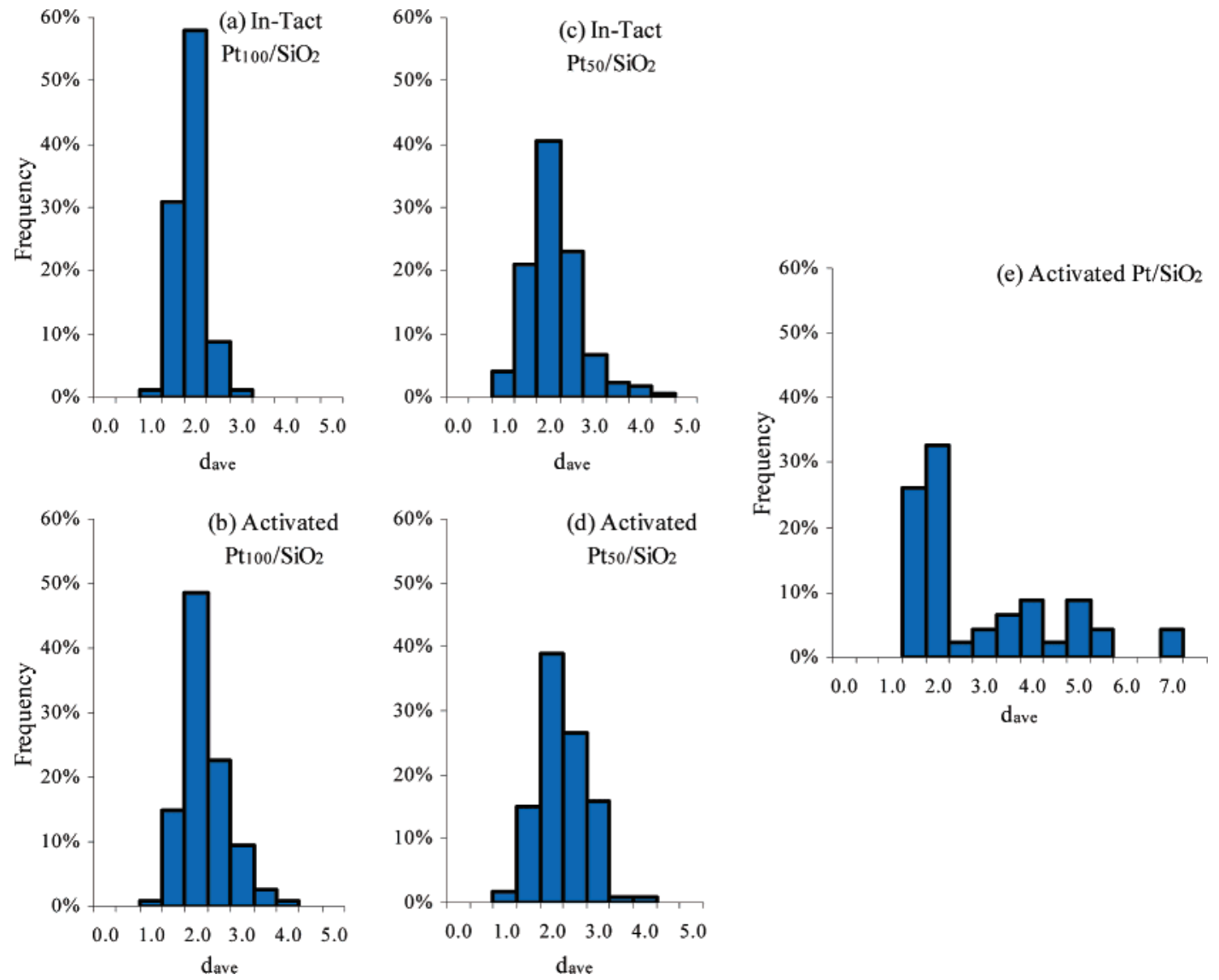

Figure 4. Particle size distribution histograms for (a) intact $\mathrm{Pt}_{100} / \mathrm{SiO}_{2}$, (b) activated $\mathrm{Pt}_{100} / \mathrm{SiO}_{2}$, (c) intact $\mathrm{Pt}_{50} / \mathrm{SiO}_{2}$, (d) activated $\mathrm{Pt}_{50} / \mathrm{SiO}_{2}$, and (e) $\mathrm{Pt}_{50} /$ $\mathrm{SiO}_{2}$.

analysis, $\mathrm{CO}$ adsorption, and average particle sizes measured from TEM, are compiled in Table 1. CO chemisorption and TEM data for the DDNCs indicate that the metal particles are small and well dispersed, and the infrared data are consistent with $\mathrm{CO}$ adsorbed on supported-Pt catalysts.

The activated catalysts were tested using the toluene hydrogenation and $\mathrm{CO}$ oxidation test reactions. Figure 5 presents $\mathrm{CO}$ oxidation light-off curves (plots of conversion vs temperature at constant space velocity), and Table 2 contains data extracted from the catalysis experiments. Toluene hydrogenation Arrhenius plots yielded nearly identical apparent activation energies $\left(E_{\text {app}}\right)$ for all three catalysts. Rates at $60{ }^{\circ} \mathrm{C}$ (Table 2 ) show some differences between catalysts in total activity. However, toluene hydrogenation turnover frequencies (TOFs), which correct the overall rate for the available surface $\mathrm{Pt}$, were essentially the same for all three catalysts.

$\mathrm{CO}$ oxidation light off curves (Figure 5a) for the activated catalysts show that the DDNCs are more active than the traditionally prepared $\mathrm{Pt} / \mathrm{SiO}_{2}$ catalyst. The TOF vs temperature plots (Figure 5b) are derived from the conversion data, correcting for the slight differences in platinum loading and dispersion. After these corrections, the catalytic activity of $\mathrm{Pt}_{100} /$ $\mathrm{SiO}_{2}$ is indistinguishable from $\mathrm{Pt} / \mathrm{SiO}_{2}$. The $\mathrm{CO}$ oxidation tests also show $\mathrm{Pt}_{50} / \mathrm{SiO}_{2}$ to be distinct from the other two catalysts. The onset of activity by this catalyst is $25-30{ }^{\circ} \mathrm{C}$ lower than with $\mathrm{Pt} / \mathrm{SiO}_{2}$, TOFs for $\mathrm{Pt}_{50} / \mathrm{SiO}_{2}$ are 2.5-3 times higher than the other catalysts, and the apparent activation energy extracted from the TOF data (Table 2) is $3 \mathrm{kcal} / \mathrm{mol}$ lower. 
(a) CO Conversion

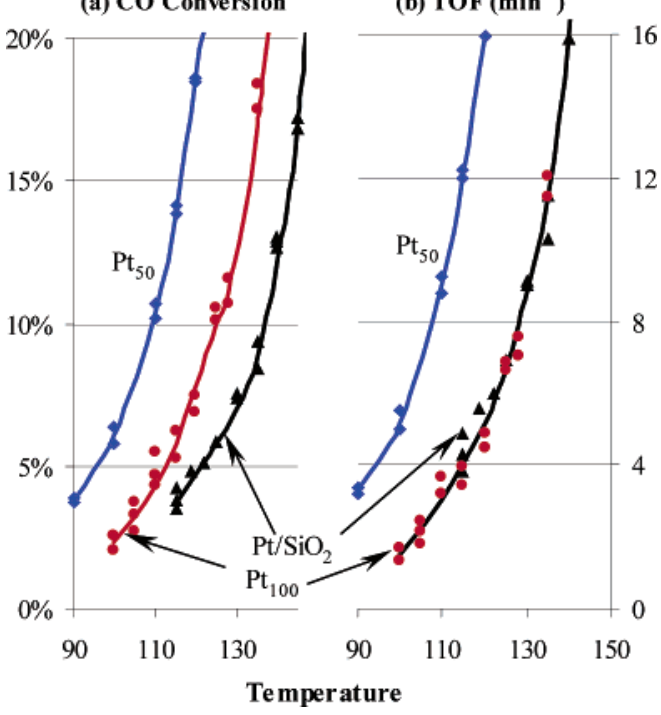

Figure 5. CO oxidation catalysis for after oxidation at $300{ }^{\circ} \mathrm{C}\left(20 \% \mathrm{O}_{2} /\right.$ $\mathrm{He}, 4 \mathrm{~h})$ and reduction at $300{ }^{\circ} \mathrm{C}\left(20 \% \mathrm{H}_{2} / \mathrm{He}, 2 \mathrm{~h}\right)$.

Table 2. Catalysis Data for Traditional and DEN Catalysts

\begin{tabular}{lccc}
\hline & $\mathrm{Pt} / \mathrm{SiO}_{2}$ & $\mathrm{Pt}_{100} / \mathrm{SiO}_{2}$ & $\mathrm{Pt}_{50} / \mathrm{SiO}_{2}$ \\
\hline \multicolumn{4}{c}{ Toluene Hydrogenation } \\
rate at $60{ }^{\circ} \mathrm{C}\left(\mathrm{s}^{-1}\right)$ & 0.057 & 0.085 & 0.069 \\
$\mathrm{TOF}\left(\mathrm{s}^{-1}\right)$ & 0.13 & 0.13 & 0.14 \\
$E_{\text {app }}(\mathrm{kcal} / \mathrm{mol})$ & 13.7 & 13.6 & 13.8 \\
\multicolumn{4}{c}{ CO Oxidation } \\
$T_{25}\left({ }^{\circ} \mathrm{C}\right)^{a}$ & 150 & 141 & \\
$E_{\text {app }}(\mathrm{kcal} / \mathrm{mol})$ & 17.5 & 17.5 & 125 \\
\hline
\end{tabular}

${ }^{a}$ Temperature required for $25 \%$ conversion.

\section{Discussion}

PAMAM dendrimers have been used to template and stabilize dendrimer encapsulated nanoparticles (DENs) of Pt, Pd, Au, $\mathrm{Cu}$, and $\mathrm{Ru} .^{3,11} \mathrm{DENs}$, particularly those of noble metals, offer a number of opportunities for the study of heterogeneous catalysts. Because DENs can be prepared and purified in aqueous solution, they can then be delivered to any number of solid carriers. This allows for the delivery of nanoparticles with known and reproducible synthetic histories (or even from the same synthetic batch) to a variety of different substrates. For example, the deposition of Pt DENs onto high surface area amorphous silica, mica, and $\mathrm{Si} / \mathrm{SiO}_{2}$ TEM substrates would allow for atomic force microscopy (AFM) and TEM studies to be performed on the appropriate samples. At the same time, direct comparisons could be made with bulk catalyst activity measurements using high surface area catalysts prepared from the same batch of nanoparticles. Alternately, delivery of nanoparticles of consistent size and distribution to different supports (e.g. silica, alumina, titania, ceria) may eventually allow for the evaluation of support effects and metal-support interactions. Because the nanoparticles of conventionally prepared supported catalysts are generally prepared on the surface of the support, particle sizes and distributions are often dissimilar on different carriers, thus making the separate evaluation of support and particle size effects difficult.

The results from this study serve as the initial proof of this concept and outline the important factors for developing heterogeneous catalysts from dendrimer encapsulated nanopar- ticles. One other attempt to activate supported DENs with hightemperature oxidation has been reported. ${ }^{22}$ In this study, Sun and Crooks deposited dendrimer encapsulated Pd nanoparticles onto a flat mica support and evaluated particle mobility with AFM. They clearly showed Pd particle mobility and sintering are pronounced at very high temperatures $\left(600^{\circ} \mathrm{C}\right)$ but did not address activation under more moderate conditions. In this study, we monitored the decomposition of the PAMAM dendrimer using in-situ infrared spectroscopy to explore the possibility of activating the supported DENs at lower temperature. Particle agglomeration processes on oxide supports are expected to be much faster at higher temperatures, so identifying low-temperature activation processes is critical to eventually realizing the possible advantages of the dendrimer route to model, study, and develop industrially relevant supported catalysts.

The decomposition experiments illustrated in Figure 1 indicate that the amide bonds of the PAMAM dendrimers are largely destroyed after oxidation at $300{ }^{\circ} \mathrm{C}$. However, $\mathrm{CO}$ oxidation experiments on oxidized supported DENs (Figure 2) show that the nanoparticles are not very active catalysts. Further treatment with $\mathrm{H}_{2}$ at $300{ }^{\circ} \mathrm{C}$ yielded catalysts active for oxidation and hydrogenation reactions. Elemental analysis confirms that most of the $\mathrm{C}$ and $\mathrm{N}$ have been removed, but the relatively high detection limits do not exclude the persistence of some organic residues on the catalyst surface.

On the basis of a 100 atom spherical Pt particle, the expected dispersion (\% surface $\mathrm{Pt}$ ) and average particle sizes for $\mathrm{Pt}_{100} /$ $\mathrm{SiO}_{2}$ are $78 \%$ and $1.4 \mathrm{~nm}$, respectively. The chemisorption data $\left(66 \%, d_{\text {calc }}=1.7 \mathrm{~nm}\right)$, which inherently samples a much greater number of particles than is possible with TEM, is in reasonably good agreement with the expected value and indicates that there has been little particle agglomeration during the activation of $\mathrm{Pt}_{100} / \mathrm{SiO}_{2}$. The particles imaged with TEM also have a slightly larger average diameter than the expected value and the chemisorption value, which is consistent with the literature reports of Pt and Pd DENs ${ }^{3,11}$ and with the presence of the support (vida infra). After the activation protocol, the average diameter and size distribution change only slightly.

The three-dimensional nature of the support complicates interpretation of the TEM data in two ways: (1) The threedimensional landscape of the support makes it difficult to find areas of relatively consistent thickness necessary to obtain good contrast between the nanoparticles and the support. (2) Since the nanoparticles are dispersed throughout this three-dimensional support, they are often in different focal planes, making many of the particles in a given micrograph slightly out of focus. Given these factors, the differences in TEM particle size before and after activation may not be significant. At most, they represent only a small increase in average particle size. The high chemisorption value also suggests that the TEM measurements may slightly overestimate the actual average particle size, either through this inherent imprecision in measuring the observed particles or through undercounting of the smaller particles.

TEM data from $\mathrm{Pt}_{50} / \mathrm{SiO}_{2}$ also show little to no change in average particle size and distrubution resulting from the activation protocol. However, the particles are larger than would be expected for a 50 atom particle, suggesting that metal aggregation has occurred during the deposition process. In the preparation of the catalyst via wetness impregnation, the volume

(22) Sun, L.; Crooks, R. M. Langmuir 2002, 18, 8231-8236. 
of the $\mathrm{Pt}_{50}$ solution had to be concentrated to a greater extent than the $\mathrm{Pt}_{100}$ solution to maintain consistent $\mathrm{Pt}$ loading. Concentrating this solution prior to deposition would be expected to foster some degree of particle agglomeration during deposition.

After activation, the TEM particle size distributions for the DDNCs are very similar. $\mathrm{CO}$ uptake by $\mathrm{Pt}_{50} / \mathrm{SiO}_{2}$, however, is somewhat lower than $\mathrm{Pt}_{100} / \mathrm{SiO}_{2}$. This may be due to the persistence of organic residues on the catalyst surface. If the metal loadings are to remain consistent, depositing the $\mathrm{Pt}_{50}$ DENs necessitates doubling the dendrimer loading relative to the $\mathrm{Pt}_{100}$ DENs. It is perhaps not surprising that a single activation protocol is not optimal for catalysts with such different dendrimer loadings as the $\mathrm{Pt}_{50} / \mathrm{SiO}_{2}$ catalyst has more organic material to remove. Our continuing work is aimed at addressing the differences in activation conditions and optimizing conditions for individual catalysts.

Infrared spectra of $\mathrm{CO}$ adsorbed to the dendrimer-derived nanoparticle catalysts (DDNCs) are consistent with $\mathrm{CO}$ bound to supported Pt catalysts. ${ }^{19}$ The CO stretching frequencies (Table 1) are similar for all three catalysts, with the DDNCs slightly blue shifted relative to $\mathrm{Pt} / \mathrm{SiO}_{2}$. Figure 3 also shows that the DDNC peak shapes are more narrow and symmetrical than the $\mathrm{Pt} / \mathrm{SiO}_{2}$ catalyst, suggesting that the surface platinum sites on the DDNCs are more uniform than on the conventionally prepared catalyst. This result is consistent with the TEM data, which show more narrow particle size distributions for the DDNCs.

Toluene hydrogenation and $\mathrm{CO}$ oxidation catalysis were chosen as test reactions that are representative of the broad range of reactions for which supported Pt catalysts are active. Toluene hydrogenation is particularly attractive because it is well-known as a structure insensitive reaction on monometallic $\mathrm{Pt}$ and $\mathrm{Pd}$ catalysts. ${ }^{23}$ By the term "structure insensitive", we mean that the reaction rate depends only on the number of exposed metal atoms; i.e., the turnover frequency for this reaction is independent of particle size and does not measurably change on various surface planes. ${ }^{24}$ Thus, although rates for toluene hydrogenation at $60{ }^{\circ} \mathrm{C}$ are slightly different for the three catalysts, the turnover frequencies (TOFs) are the same when correcting for available surface Pt measured with CO chemisorption (Table 2). Similarly, the apparent activation energies $\left(E_{\mathrm{app}}\right)$ for toluene hydrogenation (Table 2) are the same for all the catalysts, consistent with the reaction's structure insensitivity. ${ }^{23}$ This structure insensitivity makes toluene hydrogenation a useful test reaction because it directly tests the activity of the available surface platinum, regardless of particle size or morphology. This reaction also provides an additional indirect estimate of exposed metal atoms that is consistent with the $\mathrm{CO}$ chemisorption data for all three catalysts.

$\mathrm{CO}$ oxidation catalysis results highlight some of the potential of the dendrimer route. $\mathrm{Pt}_{100} / \mathrm{SiO}_{2}$ shows slightly higher activity

(23) Lin, S. D.; Vannice, M. A. J. Catal. 1993, 143, 554-562.

(24) Bennet, C. O.; Che, M. Adv. Catal. 1989, 36, 55-172.
(Figure 5a) than the conventional catalyst, which is internally consistent with the higher dispersion of $\mathrm{Pt}_{100} / \mathrm{SiO}_{2}$. Once the total activity is corrected for the number of available $\mathrm{Pt}$ atoms (Figure 5b), there are no significant differences in $\mathrm{CO}$ oxidation TOFs. This result shows that DDNCs are appropriate models for traditionally prepared catalysts and indicates that the small amount of chlorine left on the $\mathrm{Pt} / \mathrm{SiO}_{2}$ catalyst does not substantially affect $\mathrm{CO}$ oxidation catalysis.

$\mathrm{Pt}_{50} / \mathrm{SiO}_{2}$ is clearly more active for $\mathrm{CO}$ oxidation than the other two catalysts. At all of the temperatures studied, TOFs for $\mathrm{Pt}_{50} / \mathrm{SiO}_{2}$ are 2-3 times greater than TOFs for $\mathrm{Pt}_{100} / \mathrm{SiO}_{2}$ and $\mathrm{Pt} / \mathrm{SiO}_{2}$. We are currently investigating the origination of this enhanced activity and are considering several possibilities. The TEM and CO chemisorption data suggest that small amount of organic residues may persist on this catalyst. These might affect $\mathrm{CO}$ oxidation catalysis by breaking up islands of $\mathrm{CO}$ that may serve effectively as poisons for some active sites ${ }^{25}$ or by affecting the availability of weakly bound $\mathrm{O}$ atoms. ${ }^{26}$ We cannot rule out that there may be differences in the surface oxidation state of these catalysts or perhaps the presence of a different particle morphology.

\section{Conclusions}

In this study, we show that dendrimer-encapsulated noble metal nanoparticles can be used as precursors to supported metal particle catalysts. Activation conditions were chosen on the basis of in-situ infrared spectroscopy experiments, which showed that the decomposition of PAMAM dendrimer amide bonds was largely completed after treatment at $300{ }^{\circ} \mathrm{C}$ for several hours. Further treatment with hydrogen at $300{ }^{\circ} \mathrm{C}$ was also required to prepare active catalysts, and this activation protocol caused little sintering of the metal nanoparticles. The resulting catalysts are active for both oxidation and hydrogenation reactions and prove to be appropriate models for traditionally prepared supported catalysts.

Acknowledgment. We are very grateful to Stephen Maldonado and Prof. Keith Stevenson at the University of Texas at Austin for their assistance in obtaining TEM data. This research was supported by an award from Research Corp. Acknowledgment is also made to the donors of the Petroleum Research Fund, administered by the American Chemical Society, and the National Science Foundation (Grant CTS-030135) for partial support of this research. R.A.M. gratefully acknowledges support from the Welch Foundation (Departmental Grant W-0031). We also thank the National Science Foundation (Grant CHE-0116731) for support of the chemisorption instrumentation.

Supporting Information Available: A complete experimental section. This material is available free of charge via the Internet at http://pubs.acs.org.

JA0364120

(25) Fanson, P. T.; Delgass, W. N.; Lauterbach, J. J. Catal. 2001, 204, 35-52.

(26) Bourane, A.; Bianchi, D. J. Catal. 2002, 209, 126-134. 